\title{
OSA - a risk factor for stroke
}

\author{
This article was published in the following Dove Press journal: \\ ChronoPhysiology and Therapy \\ 2 December 2011 \\ Number of times this article has been viewed
}

\section{Clodagh M Ryan}

Centre for Sleep Health and Research, University of Toronto/Toronto

General Hospital, Toronto, Canada

Correspondence: Clodagh M Ryan 9N-967 Toronto General Hospital, Toronto, Ontario, M5G 2N2, Canada Tel +I $416340-4719$

Fax +I 4I6340 4I97

Email clodagh.ryan@uhn.on.ca
Abstract: Obstructive sleep apnea is a sleep breathing disorder characterized by recurrent and intermittent hypoxia with continued respiratory effort against a closed glottis. The result of this is a cascade of acute and chronic systemic pathophysiological responses that cause endothelial dysfunction, atherosclerosis and lead to cardiovascular and cerebrovascular disease. This article focuses on the clinical evidence linking obstructive sleep apnea and stroke and on the specific mechanisms perpetuating stroke risk in this population.

Keywords: stroke, obstructive sleep apnea, brain injury, atherosclerosis, continuous positive airway pressure, outcomes

\section{Introduction}

Stroke is a devastating illness and the second leading cause of death worldwide. The vast majority of strokes are ischemic and result from a transient or permanent reduction in cerebral blood flow to a specific territory of brain. Primary prevention of stroke is key as the effect of stroke is devastating with an immediate energy failure of the brain tissue involved at the core of the ischemic territory, followed by activation of glutamate receptors, excitotoxicity, inflammation and programmed cell death. ${ }^{1}$ The ischemic penumbra is an area surrounding the infarct core, which is potentially salvageable. Recovery is possible in stroke by plasticity and tissue reorganisation. In those who have sustained a stroke, the minimisation of brain injury and prevention of a subsequent recurrence is crucial to the reduction of morbidity and mortality. Despite newer treatment strategies (eg, thrombolysis) the mortality from stroke is unchanged over the last 5-10 years., ${ }^{2,3}$ Morbidity from stroke is substantial with $20 \%$ of survivors requiring institutional care and $15 \%-30 \%$ having permanent disabilities. Despite newer primary and secondary treatment strategies the incidence of stroke is rising worldwide.

Obstructive sleep apnea (OSA) is prevalent in the general population occurring in $24 \%$ of men and $9 \%$ of women in the population. ${ }^{4}$ OSA is a sleep breathing disorder in which there is continued respiratory effort with recurrent intermittent partial or complete collapse of the pharyngeal airway resulting in partial or complete cessation of airflow. Worldwide obesity (body mass index [BMI] $\geq 30 \mathrm{~kg} / \mathrm{m}^{2}$ ) is now the fifth leading risk of death with more than $10 \%$ of the adult population considered obese. ${ }^{5}$ Studies have consistently demonstrated that weight is the strongest risk factor for OSA. ${ }^{6,7}$ It is therefore probable that a considerable percentage of the population have undiagnosed and untreated OSA.

In an era when modern medicine is targeting primary prevention of diseases, this cohort of individuals possibly represents a lost opportunity for disease modification and prevention. 
To help elucidate the potential role of OSA as a significant risk factor for stroke, I will review the available epidemiological evidence, whether or not treatment of OSA affects outcome and the pathophysiological processes linking OSA to stroke.

\section{Evidence for OSA predating stroke}

As with the association between OSA and cardiovascular disease (eg, atrial arrhythmias), exploration of the bidirectional nature of the disease has occurred. This is particularly pertinent to OSA and stroke, as brain damage to the respiratory control centre may cause sleep disordered breathing in a small number of cases. ${ }^{8}$ However, there is accumulating evidence in the literature for the presence of OSA prior to the occurrence of strokes.

A transient ischemic attack (TIA) is a brief episode of neurological dysfunction caused by focal brain, spinal cord or retinal ischemia without acute infarction. ${ }^{9}$ As TIAs are the precursor to stroke in up to $33 \%$ of patients, with a 90 day risk of stroke at $10.5 \%,{ }^{10,11}$ if OSA is present in this population, it argues for pre-existing OSA in stroke sufferers. Case reports and series suggest a high prevalence of OSA in subjects with TIA $(62 \%-69 \%) \cdot{ }^{12-14}$ A recent study has shown that OSA occurs in $43 \%$ of patients with acute TIAs, persists in the majority of cases at 90 days and is associated with a higher vascular event rate when untreated. ${ }^{15}$ Contradicting this is a matched case-control study which failed to show any significant difference in the frequency of OSA between the control and TIA groups. ${ }^{16}$ While there are conflicting reports regarding OSA in TIA patients, the majority of the studies show an increased prevalence in this population suggesting the pre-existence of OSA in stroke patients.

Secondly, a recent small study of acute stroke patients both with and without OSA demonstrated a shorter retropalatal distance in the OSA group compared to the non-OSA group. This suggests that pre-existing anatomical factors and not solely alterations in neuromuscular control or increased supine sleep as a consequence of a stroke contributed to stroke in these individuals. ${ }^{17}$ Finally, both the persistence following neurological recovery, and the absence of difference in frequency of OSA between brainstem and hemispheric strokes, the fact that OSA is more common in those with recurrent stroke, suggests that OSA may predate the development of stroke in a significant percentage of the stroke population. ${ }^{18}$

\section{Initial observations regarding link between OSA and stroke}

Clinical observations are the initial primer for most research, and the link between OSA and stroke was first described in a
1985 case report of a 34-year-old man with an acute stroke diagnosed with severe OSA. ${ }^{19}$ There was a subsequent retrospective case series in 1991 which found a prevalence of OSA in stroke patients of $72 \%, 53 \%$ and $30 \%$ when using apnea-hypopnea index (AHI) of $\geq 10,20$ and 30 respectively. ${ }^{20}$ Following these initial reports there were a series of prospective case studies and case-control studies that all reported similar high prevalences of OSA in stroke patients. This was confirmed in a meta-analysis of 29 studies which included 2343 stroke subjects, demonstrating the presence of OSA in $72 \%$ with an $\mathrm{AH}>5$ events per hour and $38 \%$ with an AHI $>20$ events per hour. ${ }^{18}$

Although these studies demonstrate an association between OSA and stroke this does not prove causality. The first evidence of a link between OSA and stroke was from a series of case-control and cross-sectional analyses of epidemiological studies using snoring as a surrogate marker for OSA. These reported increased prevalence and incidence of strokes in snorers. ${ }^{21-25}$ In the largest of these prospective studies, 71,779 women were followed for 8 years during which 398 strokes were documented. Habitual snoring increased the adjusted odds ratio of stroke by 1.33 (95\% CI, $1.06-1.67) .^{26}$

In 2001, the Sleep Heart Health Study, a community based study of 6424 subjects who had unattended home-based sleep studies, explored the relationship between sleep-disordered breathing (SDB) and self-reported cardiovascular disease including stroke. In those in whom the respiratory disturbance index (RDI) was $\geq 11$ there was an increased risk of prevalent stroke (odds ratio 1.58, 95\% CI 1.02-2.46). However, this association failed to retain significance following adjustment for BMI and hypertension. ${ }^{27}$ Subsequently data from 1475 subjects of the population based Wisconsin cohort study demonstrated a 3-fold increased adjusted risk of prevalent stroke in those with an AHI $\geq 20$ events/hour. ${ }^{28}$ This included adjustment for age, sex, BMI, alcohol, smoking, hypertension and diabetes. These investigators then performed a prospective analysis of the same cohort, excluding those subjects with prior stroke.

In the 4 year "prospective" analysis 14 subjects were found to have suffered a first-ever-stroke with an overall incidence of 1.33 per 1000 person-years. In the unadjusted model and in a model controlled for age and gender, subjects with a baseline $\mathrm{AHI} \geq 20$ had a 4-fold increased risk for an incident stroke. However, following adjustment for BMI although there was a 3-fold increased risk of stroke it failed to maintain statistical significance. The study's statistical power was limited by the small number of strokes. 
More recently, the Sleep Heart Health Study also examined the relationship between untreated OSA and incident stroke in 5422 subjects without prior stroke over an 8 year period. ${ }^{29} 193$ subjects suffered an ischemic stroke, with an overall incidence of 4.4 strokes per 1000 person-years in men and 4.5 strokes per 1000 years in women. In men, there was an almost 3-fold increased risk of stroke in those with an obstructive AHI $>25$. Furthermore, for every one unit increase in the obstructive $\mathrm{AHI}$ in men there was a $6 \%$ increase in stroke risk. In women, the increased stroke risk was not observed until the obstructive AHI was $>25$. In both men and women the increased stroke risk was associated with increasing age, systolic blood pressure, use of antihypertensive medications and atrial fibrillation.

In a North American observational clinic cohort study 1022 subjects both with and without OSA were followed for a median time of 3.3 (no sleep apnea) or 3.4 (with sleep apnea) years. ${ }^{30}$ In the OSA group the incidence of stroke or death was 3.48 per 100 person-years and in the control group 1.60 per 100 person-years. Following adjustment for sex, race, smoking status, alcohol, BMI, presence of diabetes mellitus, hyperlipidemia, atrial fibrillation and hypertension, OSA remained a significant independent predictor of stroke or death. There was also a significant trend with increasing OSA severity.

While both the Sleep Heart Health Study and Wisconsin cohort study have evaluated primarily middle-aged adults, the Vitoria Sleep Project, a Spanish cohort study, examined the risk of ischemic stroke in an elderly population with untreated OSA. ${ }^{31} 394$ subjects participated in the second phase of the study and were followed for a mean period of 4.5 years. There were 20 ischemic strokes verified during the follow-up period for an incidence of 11.28 per 1000 person-years. This also demonstrated a significant association between severe OSA and ischemic stroke (hazard ratio 2.52).

In a population with symptomatic coronary artery disease and OSA there was also a significantly increased risk of stroke (adjusted hazard ratio of 2.89), independent of age, BMI, left ventricular function, diabetes mellitus, gender, intervention, hypertension, atrial fibrillation, smoking, and a previous stroke or transient ischemic attack. ${ }^{32}$

Whether OSA is an independent predictor of stroke is still a matter of some debate. However, evidence from epidemiology and clinic based studies certainly favours OSA as having a role in the occurrence of stroke. Not only may OSA be instrumental in causing strokes but there is also evidence that in those with OSA outcomes following a stroke may be poorer.

\section{Impact of OSA on stroke outcome}

Determination of successful outcome from stroke is based on the ability of an individual to manage independently and to do activities of daily living (functional outcome), to have good quality of life and longer survival. Studies in stroke patients with OSA have shown poorer functional outcomes post stroke at 3 and 12 months, longer hospitalizations and rehabilitation, ${ }^{33,34}$ increased stroke recurrence ${ }^{35}$ and increased mortality. ${ }^{36-40}$ In a 10 year follow-up study of stroke patients both with and without OSA, the presence of OSA (defined as an $\mathrm{AHI} \geq 15$ events/hour) increased the risk of death by $75 \%$ independent of many confounders (age, sex, smoking, BMI, hypertension, diabetes mellitus, atrial fibrillation, cognition and dependency during daily living) ${ }^{41}$ Martinez-Garcia also demonstrated in a 5 year follow-up of stroke patients with moderate-severe OSA an increased mortality compared to both those with OSA treated with CPAP and those without OSA ${ }^{42}$ More recently the same group showed that in stroke patients with untreated moderate-severe OSA (AHI $\geq 20$ events/hour) there was an increased incidence of recurrent ischemic stroke independent of other cardiovascular risk factors, age and gender over a 7 year follow-up period. Furthermore, in those stroke subjects with moderate-severe OSA treated and compliant with CPAP, the risk of cardiovascular events was similar to that of those with mild OSA or without OSA. ${ }^{43}$

However, studies on the treatment of OSA post-stroke have been somewhat disappointing. There has been poor adherence and compliance with CPAP in the stroke population. Acceptance of CPAP has varied from $15 \%$ to $80 \%$ in different studies. ${ }^{36,38,44,45}$ Multiple factors are responsible for this poor tolerance, including cognitive problems, post-stroke depression and physical disabilities limiting the application of headgear. ${ }^{46}$ However, CPAP has been shown to be feasible in both the acute, ${ }^{47,48}$ subacute, ${ }^{49,50}$ and chronic phase of stroke. ${ }^{51-53}$ There have been five randomized controlled studies examining the effect of CPAP on stroke outcomes (Table 1).

Parra and colleagues performed a randomized controlled trial in acute stroke subjects with OSA (AHI $\geq 20$ ), in which 71 subjects were randomized to CPAP and 69 subjects were randomized to conventional treatment. Twenty eight percent of those randomized to CPAP refused to use it. In those randomized to CPAP compared to conventional treatment, there was a significant improvement in neurological recovery at 1 month and a delay in the occurrence of subsequent cardiovascular events, but no significant change in quality of life or mortality at 24 months. ${ }^{38}$ Bravata et al randomized 


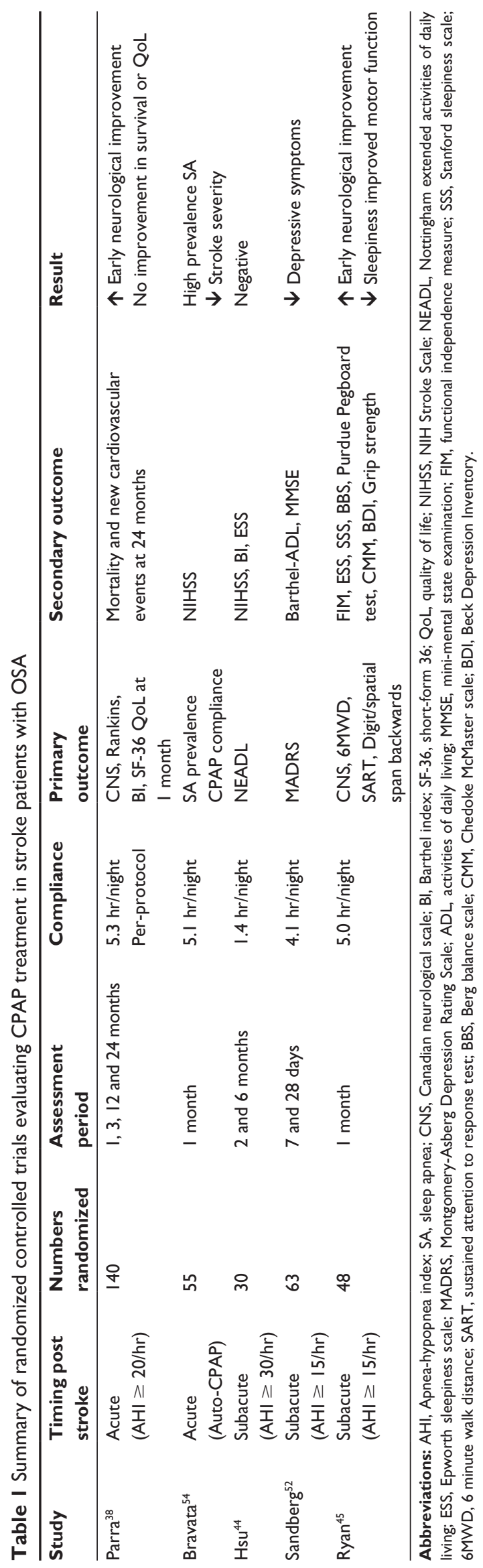

stroke patients to auto-titrating (auto)-CPAP or conventional therapy, and showed that at 30 days those in the treatment arm demonstrated a significant improvement in stroke severity. Furthermore, the greatest improvements were observed in those patients with the most auto-CPAP use ( $\geq 4$ hours for $75 \%$ of the time). ${ }^{54}$

Hsu et al performed a randomized trial in patients with OSA (AHI $\geq 30$ ) with subacute stroke (14-19 days post stroke).$^{44}$ Fifteen patients were randomized to CPAP and 15 to conventional stroke treatment. At 3 months follow-up no significant difference in functional outcomes or depressive symptoms was demonstrated. However, overall compliance with CPAP was very low and the average CPAP compliance was 1.4 hours per night. Sandberg et al randomized 59 patients with subacute stroke to CPAP or conventional therapy. Those randomized to CPAP had fewer depressive symptoms, but no change in outcome compared to the conventional group. ${ }^{52}$

Ryan et al, in a randomized study of 44 patients with subacute stroke undergoing rehabilitation showed significant improvements in motor function and the affective component of the depression score, but not in neurocognitive function following 1 month of CPAP ${ }^{45}$ Therefore, in those stroke patients who comply with CPAP treatment, early improvements in motor function and mood are demonstrated, but no significant impact in long-term outcome has been demonstrated to date. All of these studies are limited by small numbers, comorbid medical conditions and the heterogenous nature of stroke.

Treatment of OSA with bilevel positive airway pressure has been assessed. An observational study assessing the treatment of acute stroke in a cohort of subjects with persisting proximal neurological occlusions with worsening during sleep, OSA or a history of OSA with bilevel positive airway pressure, demonstrated good tolerability and possible early neurological improvement. ${ }^{55} \mathrm{~A}$ very small study on ten subjects with transnasal insufflation (a high-flow rate of air at $18 \mathrm{~L} / \mathrm{min}$ delivered through an open nasal cannula) showed good tolerability, however, minimal improvements in the AHI.$^{56}$ Much larger and long-term studies will be necessary to determine the full impact of OSA treatment on patients with stroke.

\section{Mechanisms linking OSA and stroke OSA and sleep}

Sleep has specific effects on both the autonomic and cardiovascular system. During non-rapid eye movement (NREM) sleep, respiration is almost exclusively under 
chemoreflex control, parasympathetic nervous system tone increases, and sympathetic nervous system activity, heart rate, blood pressure, stroke volume, cardiac output and systemic vascular resistance decrease.$^{57-60}$ As a result, the cardiovascular system is in a state of hemodynamic and autonomic quiescence. During rapid eye movement (REM) sleep, breathing becomes more dependent on behavioral factors $^{61-63}$ and there is an irregular pattern of breathing, and intermittent surges in heart rate, sympathetic nervous activity and blood pressure linked to phasic REM sleep events. ${ }^{57,60,63}$ NREM sleep represents $75 \%$ to $85 \%$ of sleep and it means that overall sleep is a period of cardiovascular quiescence. This may explain the lower occurrence of cardiovascular and cerebrovascular events during the night and the surge that occurs in the early morning between 6 am and noon in association with elevations in blood pressure and heart rate. ${ }^{64,65}$ However, the presence of OSA dramatically changes the normal sleep milieu and may be a factor in the higher occurrence of stroke during sleep or in the first hour of wakening in OSA subjects, reported in recent studies. ${ }^{66-68}$ In OSA there are both acute and chronic effects that may develop over time, both may predispose to the development of stroke. These mechanisms involved in the causation of stroke and sleep apnea remain incompletely understood.
However, to understand why sleep apnea poses a potential risk for stroke, it is important to have some understanding of these pathophysiological effects of OSA. The effects of OSA may occur acutely or over time (Figure 1).

\section{Acute effects of OSA}

In OSA there is recurrent arterial desaturation alternating with normoxia, resulting in systemic hypoxemia and hypercapnia. Hypoxia may reduce myocardial oxygen delivery, directly depress myocardial contractility and increase left ventricular (LV) afterload, and indirectly cause increased pulmonary vasoconstriction and increasing pulmonary arterial pressure ${ }^{69,70}$ Hypocapnia, as a result of post-apneic hyperventilation, can induce coronary vasoconstriction and a leftward shift of the oxyhemoglobin curve reducing oxygen release to the myocardium. ${ }^{71}$

Hypoxia-induced ischemia of myocardial tissue induces electrical, mechanical and biochemical dysfunction particularly in those with pre-existing cardiac dysfunction. Ischemia induced increases in intracellular $\mathrm{Ca}^{2+}$ and $\mathrm{H}^{+}$, accumulation of lipid metabolites and dephosphorylation of gap junction protein connexin 43 causes electrical uncoupling and triggers arrhythmias. $^{72,73}$

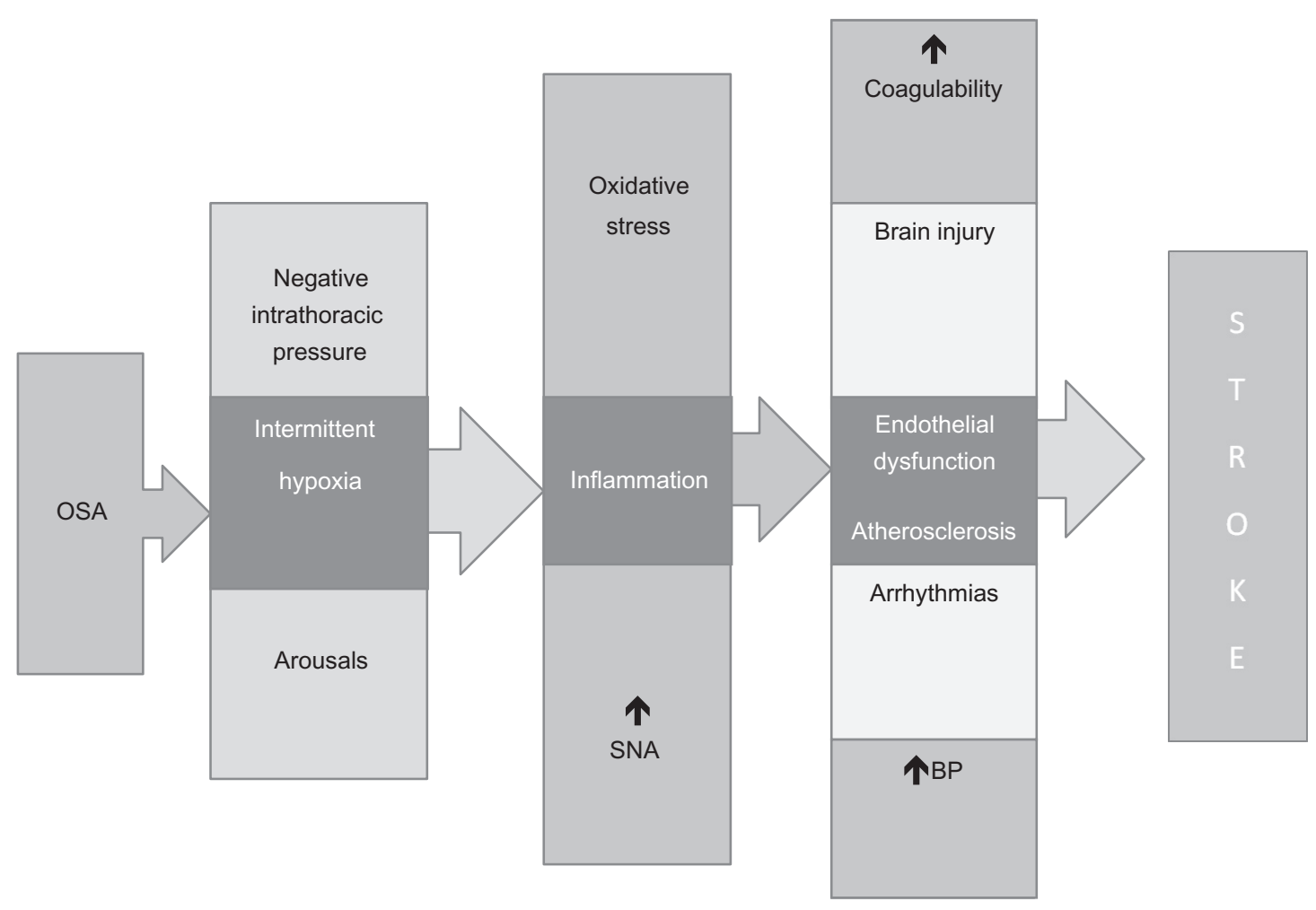

Figure I Pathophysiology of OSA.

Abbreviations: OSA, obstructive sleep apnea; $\uparrow$ SNA, increased sympathetic nervous activity; $\uparrow$ BP, hypertension; $\uparrow$ coagulability, hypercoagulability. 
Arousals are critical to the opening of the upper airway and resumption of ventilation in OSA. ${ }^{74,75}$ They may contribute to post-apneic surges in heart rate and blood pressure, ${ }^{76-78}$ sympathetic nervous system activation and catecholamine release. ${ }^{74,79}$ Repetitive arousals may contribute to increased sleep fragmentation and neurocognitive sequelae.

Futile inspiratory effort against a closed glottis as occurs in OSA results in the generation of negative intrathoracic pressure to as low as $-108 \mathrm{~cm} \mathrm{H}_{2} \mathrm{O}^{80}$ These swings in pressure result in increased venous return to the right heart with subsequent distension of the right ventricle and leftward shift of the interventicular septum during diastole. ${ }^{70}$ This adversely affects filling of the LV and causes reduced stroke volume, and delay LV relaxation. ${ }^{81}$ In turn, this may cause reductions in cerebral blood flow. ${ }^{82-84}$ The increased transmural gradients may promote excessive vessel shear stress and promote endothelial dysfunction.

\section{Chronic effects of OSA}

\section{Autonomic dysfunction}

The repetitive arousals and intermittent hypoxia cause overactivation of the sympathetic nervous system, reduced baroreflex sensitivity and heart rate variability and increased blood pressure variability in subjects with OSA through the stimulation of peripheral and central chemoreceptors. ${ }^{79,85} \mathrm{In}$ animal studies noradrenaline has been demonstrated to result in hypertrophy of the myocardium. ${ }^{86}$ There is a correlation between increased sympathetic nervous activity (SNA) and left ventricular hypertrophy in subjects with hypertension, suggesting that increased SNA may contribute to myocardial remodeling in humans.$^{87}$ Elevated SNA may perturb cerebral autoregulation and blood flow predisposing to cerebral ischemia ${ }^{88}$ Evidence from post-stroke subjects demonstrates that elevated serum noradrenaline is an independent predictor of poor outcome at 1 year. ${ }^{89}$

\section{Endothelial dysfunction and atherosclerosis}

The cyclic intermittent hypoxia is akin to a chronic ischemiareperfusion type injury that may have a direct effect on the vasculature. This oxygenation/reoxygenation injury is known to initiate oxidative stress via the production of reactive oxygen species (ROS). Increased oxidative stress denotes an imbalance between ROS production and antioxidant defence. This is recognized to play an important role in the genesis of endothelial dysfunction, via inactivation of vasodilator nitric oxide $(\mathrm{NO})^{90}$ and through the modulation of diverse redoxsensitive signaling pathways in endothelial cells which influence gene and protein expression. ${ }^{91}$ The redox-sensitive signaling pathways include nuclear factor kappa $\beta(\mathrm{NF}-\kappa \mathrm{B})$ and hypoxiainducible factor-1 (HIF-1). NF-KB activates pro-inflammatory cytokines (TNF $\alpha$, IL-6), chemokines (MCP-1 and IL-8) and adhesion molecules (ICAM, VCAM, selectin) ${ }^{92}$

There is increasing evidence that vascular wall inflammation plays a key role in the pathogenesis of vascular disease and the atherosclerotic process. ${ }^{93}$ Functional impairment signifies endothelial dysfunction, a precursor of atherosclerosis, whereas in atherosclerosis there are structural changes in the arterial walls. Vascular tone is usually maintained by the homeostatic balance between vasodilators (nitric oxide and prostacyclin) and vasoconstrictors (endothelin-1 and angiotensin II). There is good evidence that OSA is associated with endothelial dysfunction. ${ }^{94}$ Lavie and Lavie have proposed oxidative stress as the unifying mechanism between OSA and vascular disease and its associated comorbid illnesses. ${ }^{95}$ However, whether oxidative stress is a consequence or a cause of OSA is still controversial. ${ }^{96}$

In vitro models of intermittent hypoxia were the first to demonstrate activation of NF- $\mathrm{KB}^{97}$ and suggest a causative pathway between OSA and inflammation. The presence of increased oxidative stress in OSA has been assessed indirectly by markers such as oxidized LDL and thiobarbituric acidreactive substance (TBARS). The vast majority of studies in OSA have demonstrated increased oxidative stress, while only a few have failed to show this increase..$^{95}$ Non-randomized uncontrolled studies have also demonstrated activated NF- $\kappa B$ and elevated levels of its associated proinflammatory cytokines, chemokines and adhesion molecules in OSA patients, consistent with the animal models of intermittent hypoxia. ${ }^{98}$ Reduction in these markers is demonstrated following CPAP treatment. ${ }^{99-101}$ There is also an association between OSA and elevated levels of matrix metalloproteinase-9, which is activated by oxidative stress, and induces plaque rupture. ${ }^{102}$ Matrix metalloproteinases are known to disrupt the blood-brain barrier in stroke. ${ }^{103}$ While most studies in OSA have concentrated on investigating the deleterious effect of oxidative stress on the cardiovascular system, the brain is highly susceptible to oxidative damage due to the paucity of its antioxidant system and large oxygen dependency. ${ }^{104,105}$ There is limited evidence from animal studies of ROS production causing neuronal injury. ${ }^{106}$ Furthermore, in a study of 50 nonobese subjects with stroke and OSA there were increased IL-6 levels compared to a control group. The IL-6 levels were independently correlated with the oxygen desaturation index and low oxygen saturation, but not with the AHI. This may suggest inflammation as an important unifying mechanism between OSA and stroke. ${ }^{107}$ 
The intermittent hypoxia/reoxygenation of OSA also affects the function of both neutrophils and leukocytes further stimulating inflammation and atherogenesis. Evidence from Lavie and colleagues demonstrated a reduction in neutrophil apoptosis and increased selectin adhesion molecule expression in moderate-severe OSA patients that was improved by treatment with nasal CPAP. ${ }^{108}$ Delayed apoptosis of neutrophils may facilitate the increased production of ROS and hence stimulate atherogenesis. This group has also demonstrated increased activation of monocytes, CD4, CD8 and $\gamma \delta \mathrm{T}$ cells with subsequent release of ROS and endothelial cell damage. ${ }^{109-111}$

The chronic intermittent hypoxia of sleep apnea is probably responsible for activation of the renin angiotensin aldosterone system (RAAS) as demonstrated in animal studies. ${ }^{112,113}$ The RAAS is a hormonal system that controls body fluid volume, blood pressure and cardiovascular function. Angiotensin II is synthesized by and locally active on the endothelium. High plasma levels of aldosterone and angiotensin II are reported in patients with OSA. ${ }^{114}$ Angiotensin II causes an increased production of reactive oxygen species via the NADH/NADPH oxidase activation. ${ }^{115}$ Both hypoxia and angiotensin II are potent stimulators of the angiogenic cytokine vascular endothelial growth factor (VEGF), a contributor to atherogenesis. ${ }^{116}$ This RAAS activation may also contribute to elevations in blood pressure ${ }^{117}$ Therefore, overactivity of RAAS may stimulate hypertension a risk factor for stroke.

Chronic hypoxia of OSA is also implicated in the induction of hyperlipidemia and lipid peroxidation, initiation or potential aggravation of insulin resistance and diabetes mellitus through the ROS. However, the relationship between OSA and insulin resistance is still disputed. ${ }^{118}$ As insulin has vasodilatory and anti-inflammatory effects, ${ }^{119}$, insulin resistance may alter the homeostatic balance in favour of the development of atherosclerosis. Hyperglycemia and hyperinsulinemia activate the RAAS and facilitate the generation of ROS via an NADPH oxidase mechanism leading to oxidative injury. ${ }^{120}$

In summary, the nocturnal cyclic intermittent hypoxia of OSA activates systemic inflammation, oxidative stress and metabolic dysfunction which are potential precursors of endothelial dysfunction and atherosclerosis. These are complex interrelated pathways and mechanisms which have as yet to be fully elucidated.

As atherosclerosis is a marker of incident stroke, ${ }^{121-124}$ if OSA predisposes to atherosclerosis then it suggests another mechanistic pathway by which it may cause stroke.
There have been a number of studies by Drager and colleagues evaluating the role of OSA in atherosclerosis in patients compared to controls. Firstly, compared to controls, those OSA patients on no medications and without comorbid conditions had early signs of atherosclerosis. ${ }^{125}$ Secondly, when OSA subjects were compared to those with hypertension, there was similar atherosclerosis with an additive effect seen in those subjects with both OSA and hypertension. ${ }^{126}$ Furthermore, a randomized controlled trial demonstrated reductions in atherosclerosis following 4 months of CPAP treatment. ${ }^{127}$ There have been numerous other cross-sectional studies that have echoed these findings, suggesting that OSA may be an independent predictor of atherosclerosis. ${ }^{118} \mathrm{In}$ ischemic stroke patients, severe OSA has been shown to have a strong association with extracranial artery disease and peripheral arterial disease ${ }^{128}$ Furthermore, a prospective study of 214 ischemic stroke patients demonstrated that OSA was an independent risk factor of atherosclerotic artery disease independent of other vascular risk factors. ${ }^{129}$

\section{Hypertension}

Hypertension increases the risk of stroke 3 to 4 fold and is a major modifiable risk factor for stroke. ${ }^{130}$ Hypertension induces remodelling of systemic and cerebral blood vessels and promotes atherosclerosis. ${ }^{131}$ In normal subjects there is a reduction in nocturnal blood pressure compared to wakefulness by $10 \%-20 \%$. This is called nocturnal dipping of the blood pressure. Attenuated nocturnal blood pressure dipping has been associated with greater leukoaraiosis. ${ }^{132}$ The Dublin Outcome Study has shown that a 10\% increase in nocturnal systolic blood pressure was associated with a $21 \%$ increase in cardiovascular morbidity ${ }^{133}$ and a meta-analysis of randomized controlled trials on the treatment of hypertension demonstrated that for a $10 \mathrm{~mm} \mathrm{Hg}$ reduction in SBP and $5 \mathrm{~mm} \mathrm{Hg}$ reduction in DBP there was a $41 \%$ relative risk reduction in stroke. ${ }^{134}$ In OSA, hypertension may result from intermittent hypoxia associated activation of the RAAS, sympathetic activation, ${ }^{70,85}$ altered chemoreceptor sensitivity ${ }^{135}$ and up-regulation of endothelin-1 receptors. ${ }^{136}$

Evidence in support of OSA as a cause of hypertension includes: (1) the dose-dependent linear relationship between OSA and elevated arterial blood pressure; ${ }^{137}$ (2) crosssectional studies demonstrating an increased risk of prevalent hypertension in those with OSA; (3) a reduction in blood pressure in OSA subjects treated with CPAP. ${ }^{138-140}$

Both the Sleep Heart Health Study and the Wisconsin cohort studies have demonstrated an independent association 
between OSA and prevalent hypertension following adjustment for confounders including obesity. ${ }^{137,141}$ The Wisconsin cohort study, a population-based study, demonstrated a 3-fold increased risk of incident hypertension following adjustment for body mass index in OSA subjects with an AHI $>15$ events per hour. ${ }^{142}$ However, the Sleep Heart Health study failed to demonstrate that OSA was a significant risk factor for incident hypertension following adjustment for BMI. ${ }^{143}$ In patients with resistant hypertension the prevalence of OSA is high at $83 \%^{144}$ and OSA may be an independent predictor. ${ }^{145}$ Treatment of OSA by CPAP has been demonstrated to have modest effects in the reduction of blood pressure. ${ }^{138-140}$

Following an acute stroke, alterations in blood pressure control occur. There is a loss of circadian variation with an absence of the nocturnal dipping and the presence of low or high blood pressure is associated with poorer outcomes. ${ }^{146-149}$ In subjects with OSA and acute stroke there is greater blood pressure variability, ${ }^{39}$ a factor known to be associated with poorer outcomes. A small prospective study of 41 subjects with sleep apnea and an ischemic stroke showed that severe sleep apnea $($ AHI $>30)$ was associated with greater 24 hour blood pressure values. ${ }^{150}$ However, larger studies are necessary to evaluate more fully the impact of OSA on acute stroke both in the short and long term.

\section{Hypercoagulability}

Hypercoagulability may predispose to acute thrombosis and subsequent cerebrovascular events. ${ }^{151,152}$ Altered hypercoagulability occurs by a variety of mechanisms in OSA. Studies to date have demonstrated alterations in platelet activation, plasminogen activator inhibitor-1 (PAI) and fibrinogen in OSA subjects but are not conclusive. Increased platelet aggregability and markers of hypercoagulation including plasma fibrinogen, plasma viscosity and d-dimers, erythrocyte adhesiveness, and PAI have been demonstrated in sleep disordered breathing ${ }^{153-155}$ with reductions in nonrandomized studies following CPAP. ${ }^{156,157}$ RAAS activation and hypoxia may contribute to activation of $\mathrm{PAI}^{158}$ in OSA. Platelet, coagulation factors and fibrinogen follow a circadian pattern. Platelet aggregation increases between 6 am and noon. Tissue-type plasminogen activator concentrations and PAI peak after 6am causing reductions in fibrinolytic activity. However, in OSA, peaks in these factors occur during the night. ${ }^{159-162}$ Therefore, in OSA there may be exaggeration and shift in the timing of the usual circadian variation in platelet aggregability and markers of hypercoagulation.

\section{Arrhythmias}

A number of serious cardiac arrhythmias have been described in association with OSA including sinus pauses, heart block, atrial and ventricular tachycardia. ${ }^{163}$ In OSA, the generation of negative intrathoracic pressure will cause stretch and remodeling of the atria and pulmonary vein ostia predisposing to conduction abnormalities.

In a cross-sectional analysis of the Sleep Heart Health Study, a prospective epidemiology trial, there was a 4 -fold increase in atrial fibrillation, 3-fold increase in non-sustained ventricular tachycardia and 2-fold increase in the odds of complex ventricular ectopics in those with severe sleep disordered breathing (respiratory disturbance index $\geq 30$ ) compared to those without, after adjustment for potential confounders including BMI, age, sex and prevalent coronary heart disease. ${ }^{164}$ In the MrOS study a strong association between sleep apnea and arrhythmia occurrence was also noted. ${ }^{165}$ Atrial fibrillation is a major risk factor for stroke. While the first association between atrial arrhythmias and sleep apnea occurred in the $1980 \mathrm{~s},{ }^{166}$ it has been in the last few years that there has been an explosion of research assessing the link between OSA and atrial fibrillation.

Kanagala et al demonstrated prospectively that in a group of patients undergoing DC cardioversion for atrial fibrillation there was an increased recurrence rate in those with either untreated OSA or non-compliant with OSA therapy (82\%) compared with those compliant $(42 \%, P=0.013)$ and those without OSA $(53 \%, P=0.009) .{ }^{167}$ In patients without cardiac disease or known arrhythmias the prevalence of atrial arrhythmias in 247 patients with OSA (defined as AHI $>5 /$ hour) was $6.1 \%$ with less than $1 \%$ with atrial fibrillation. ${ }^{168}$ More recently a population-based Japanese study demonstrated an association trend between the severity of OSA as defined by the $3 \%$ oxygen desaturation index (ODI) and atrial fibrillation following adjustment for age, BMI, smoking, systolic hypertension and antihypertensive medications. The adjusted odds ratio for mild (ODI 5-15/hour) was 2.47 and 5.66 for moderate to severe SDB (ODI $\geq 15 /$ hour). The adjusted prevalence for atrial fibrillation was $1.9 \%$ for mild SDB and $4.9 \%$ for moderatesevere SDB $(P<0.001) .{ }^{169}$ In a retrospective study of 3542 subjects for the occurrence of incident atrial fibrillation OSA was present in $74 \%$ of the subjects and there was a mean follow-up of 4.7 years. The presence of OSA $(\mathrm{AHI}>5)$ was a strong predictor of incident atrial fibrillation (HR 2.181-3.54, $P=0.002$ ). Atrial fibrillation occurred in $4.3 \%$ with OSA and $2.1 \%$ without OSA. ${ }^{170}$ 


\section{Patent foramen ovale}

Patent foramen ovale (PFO) is prevalent in the general population, occurring in $27 \%-35 \%$ of hearts at autopsy and in $10 \%-26 \%$ of individuals undergoing transesophageal echocardiography (TEE) with contrast. ${ }^{171} \mathrm{PFO}$ is significantly associated with cryptogenic stroke in both young and old subjects. ${ }^{172}$ The prevalence of PFO in stroke varies between $20 \%-54 \%$. Increased stroke risk in those with PFO is associated with the magnitude of the right to left shunting, size of the $\mathrm{PFO}$ and other factors such as the excursion of the interatrial septa into either atrial cavity, persistent Chiari networks, prominent Eustachian valves ${ }^{171}$ and prothrombotic state. ${ }^{173}$ Obviously due to the high prevalence in the general population both OSA and PFO may coexist. There have been three small studies done that have reviewed the prevalence of $\mathrm{PFO}$ in OSA. Prevalences of PFO were variable (26.9\%-68.8\%), with two studies suggesting increased prevalence compared to the general population. ${ }^{174,175}$ Furthermore, in subjects with PFO and OSA, right to left shunting was observed during obstructive apneas lasting $>17$ seconds ${ }^{175}$ and there may be more severe nocturnal oxygen desaturation. The negative intrathoracic pressure which occurs during apnea episodes leads to increased venous return to the right heart which favours right to left shunting. Therefore, the combination of a PFO and OSA may predispose to increased stroke risk by potentially causing paradoxical embolism and increased right to left shunting.

\section{Physical inactivity}

Regular physical activity has been documented to have beneficial effects for stroke reduction in both men and women in several epidemiological and cardiovascular long-term studies. ${ }^{176}$ Mediation of this stroke risk reduction in association with physical activity may occur by reductions in blood pressure, weight, diabetes and reduced fibrinogen and platelet activity. ${ }^{177,178}$ In two cross-sectional studies, physical inactivity is significantly associated with OSA following adjustment for confounding variables including age, BMI and sleepiness. ${ }^{179,180}$ However, in an APPLES sub-study, the reduction in physical activity in the OSA group was primarily explained by decreased physical activity related to obesity, ${ }^{181}$ although the number of subjects in this study was considerably smaller than in the Wisconsin cohort study. ${ }^{180}$ In a double blind parallell randomized controlled trial in which OSA subjects were treated with CPAP or placebo, there was no increase in physical activity observed in the treated OSA subjects despite a reduction in sleepiness. The authors conclude that this may be due to longstanding habitual patterns in these patients. ${ }^{182}$
More recent evidence linking physical inactivity to OSA has come from Bradley and colleagues. ${ }^{183}$ In evaluating the role of fluid shifts in the pathogenesis of OSA they have also shown that in those who spend greater periods of the day sitting (physically inactive) there is increased shift of fluid from the legs to the neck overnight which is strongly linked to the AHI. ${ }^{183}$

\section{Brain injury}

In order to meet its metabolic demands the brain is highly dependent on an adequate cerebral blood flow. Cerebral blood flow changes in response to cerebral perfusion pressure, $\mathrm{PaCO}_{2}$, $\mathrm{PaO}_{2}$, arterial oxygen content and blood viscosity. Changes in cerebral perfusion pressure over a wide range, from 50 to $170 \mathrm{~mm} \mathrm{Hg}$, have little effect on cerebral blood flow. Cerebral autoregulation is the compensatory mechanism by which cerebral blood flow remains relatively constant during variation of cerebral perfusion pressure from 50 to $170 \mathrm{mmHg}$. It is mediated by changes in cerebrovascular resistance. Cerebral autoregulation is a complex homeostatic mechanism that is dependent on multiple factors including myogenic, neuronal, endothelial and metabolic. It remains unaltered with age and hypertension. However, it has been shown to change under physiological and pathological conditions such as exercise, stroke, and carotid artery disease. Cerebral blood flow responds to increases in $\mathrm{PaCO}_{2}$ by vasodilation and a subsequent increase in cerebral blood flow and to decreases in $\mathrm{PaCO}_{2}$ by vasoconstriction and a subsequent decrease in cerebral blood flow (cerebrovascular reactivity). Cerebral blood flow is less responsive to changes in blood viscosity and does not increase until $\mathrm{PaO}_{2}$ is reduced below $50 \mathrm{~mm} \mathrm{Hg}$.

Decreased cerebral blood flow velocity during wakefulness and during apneas in OSA subjects has been demonstrated. ${ }^{82-84}$ It is not clear whether the intermittent hypoxia, or reduction in blood flow as a result of OSA, or possible increases in perfusion pressure or shear stress are the mediators of potential ischemic brain injury. A recent large population-based study of OSA subjects has shown impaired daytime hypercapnic cerebrovascular reactivity in a continuum from mild to severe OSA. ${ }^{184}$ In view of the recurrent nocturnal hypoxia in OSA and the risk of recurrent hypoxic insult, protection of the brain is dependent on an adequate cerebral vascular response. Failure of the cerebral circulation to respond to hypoxia or hypercapnia may result in hypoperfusion of the brain, ${ }^{88}$ leading to impaired neural function and an increased risk of cerebral ischemia and stroke. Impaired vascular reactivity to carbon dioxide may also exaggerate the accumulation and washout of carbon dioxide from central chemoreceptors causing breathing instability during sleep. 
A guinea pig animal model has shown that recurrent apneas result in cell death by apoptosis in the hippocampus and forebrain regions. ${ }^{185}$ Such neuronal damage can lead to cognitive impairment. ${ }^{186,187}$ Indeed, altered neuronal metabolism during nocturnal oxygen desaturations in OSA has been demonstrated. ${ }^{188}$ Furthermore, consistent with neuronal damage, deficits in executive function and verbal memory occur particularly in those with moderate to severe OSA. ${ }^{186,187,189}$

Overt cerebral damage is not obvious on routine MRI scans for most subjects with OSA. However, newer MRI modalities including spectroscopy and diffusion tensor imaging demonstrate white matter injury (leukoaraiosis) compared to controls ${ }^{190}$ in addition to regional grey matter loss in OSA subjects. ${ }^{189,191-193}$ Leukoaraiosis is a strong predictor of both stroke risk and outcome from stroke ${ }^{194}$ and interestingly two recent small studies have suggested that leukoaraiosis may result from white matter infarction in some instances. ${ }^{195,196}$ Canessa et al also demonstrated that cognitive impairment associated with grey matter volume reduction can be reversed by treatment of the OSA and that these structural brain abnormalities occurred in regions susceptible to hypoxic injury. ${ }^{193}$ In summary, the presence of OSA may cause alterations in cerebral perfusion, response of cerebral blood vessels to insult, and neuronal cell damage in susceptible brain tissue, which can predispose to increased stroke risk.

\section{How to determine presence of OSA in stroke subjects?}

Determination of the presence or absence of OSA in stroke subjects is difficult without the performance of an overnight in-laboratory or portable sleep study. ${ }^{197}$ Traditional symptoms including daytime sleepiness and snoring may be absent. Arzt and colleagues showed that compared to a community sample, those subjects with stroke with or without OSA had less subjective daytime sleepiness as measured by the Epworth sleepiness scale and lower body mass index. ${ }^{198}$ Both the absence of daytime sleepiness and lower body mass index is also seen in many of the observational studies. ${ }^{18}$ The Berlin Questionnaire is a validated questionnaire for the determination of OSA risk. ${ }^{199}$ Yet, in the acute stroke population it failed to predict those at high risk of OSA (positive predictive value $63.4 \%$, negative predictive value $58.8 \%) .{ }^{200}$ The presence of nocturia may help identify those with OSA. In a prospective study of 65 consecutive subjects with ischemic stroke, nocturia was an independent predictor of severe OSA $(\mathrm{OR}=3.5) \cdot{ }^{201}$ Results from a meta-analysis indicate that recurrent stroke may also be an indicator of the presence of OSA. ${ }^{18}$ Determination of the presence or absence of OSA in stroke patients through history and examination may be inaccurate, and reliance on the usual predictors of stroke in this population is not recommended.

\section{Conclusion}

In summary, the epidemiology evidence suggests a significant relationship between OSA and stroke and there are multiple pathophysiological pathways by which OSA may predispose to stroke.

In view of the significant toll of stroke on the individual and society it is imperative that the medical community continue to develop strategies for both prevention and intervention in stroke. Strategies for comprehensive acute, chronic and preventive care of stroke should be complemented with evaluation for the presence or absence of OSA. Recent clinical studies have bolstered the evidence for the treatment of those with moderate to severe OSA in the general population. In patients who have sustained a cerebrovascular event there is evidence of a potential benefit by treatment with CPAP. There are key pathophysiological mechanisms which can explain the deleterious effect of OSA on the brain. However, further research is needed to: (1) identify those subjects with OSA most at risk of stroke; (2) in the post-stroke population have testing strategies to quickly and easily identify those with OSA; (3) determine those who would benefit most from treatment and (4) develop alternative modalities of treatment which would be better tolerated by the stroke population.

\section{Disclosure}

1. Co-investigator for CIHR funded ADVENT study with unrestricted grant from Phillips-Respironics.

2. Ontario Thoracic Society: Breathe New Life Award 2011.

\section{References}

1. Dirnagl U, Iadecola C, Moskowitz MA. Pathobiology of ischaemic stroke: an integrated view. Trends Neurosci. 1999;22(9):391-397.

2. Goldstein LB, Adams R, Alberts MJ, et al. Primary prevention of ischemic stroke: a guideline from the American Heart Association/ American Stroke Association Stroke Council: cosponsored by the Atherosclerotic Peripheral Vascular Disease Interdisciplinary Working Group; Cardiovascular Nursing Council; Clinical Cardiology Council; Nutrition, Physical Activity, and Metabolism Council; and the Quality of Care and Outcomes Research Interdisciplinary Working Group. Circulation. 2006;113(24):e873-e923.

3. Sacco RL, Adams R, Albers G, et al. Guidelines for prevention of stroke in patients with ischemic stroke or transient ischemic attack: a statement for healthcare professionals from the American Heart Association/ American Stroke Association Council on Stroke: co-sponsored by the Council on Cardiovascular Radiology and Intervention: the American Academy of Neurology affirms the value of this guideline. Circulation. 2006;113(10):e409-e449. 
4. Young T, Palta M, Dempsey J, Skatrud J, Weber S, Badr S. The occurrence of sleep-disordered breathing among middle-aged adults. $N E n g l$ J Med. 1993;328(17):1230-1235.

5. Mendis S, Puska P, Norrving B. Global atlas on cardiovscular disease prevention and control: World Health Organisation in collaboration with the World Heart Federation and World Stroke Organisation, 2011. Available from: http://whqlibdoc.who.int/publications/2011/9789241564373_eng. pdf. Accessed November 16, 2011.

6. Peppard PE, Young T, Palta M, Dempsey J, Skatrud J. Longitudinal study of moderate weight change and sleep-disordered breathing. JAMA 2000;284(23):3015-3021.

7. Young T, Shahar E, Nieto FJ, et al. Predictors of sleep-disordered breathing in community-dwelling adults: the Sleep Heart Health Study. Arch Intern Med. 2002;162(8):893-900.

8. Dyken ME, Im KB. Obstructive sleep apnea and stroke. Chest. 2009;136(6):1668-1677.

9. Easton JD, Saver JL, Albers GW, et al. Definition and evaluation of transient ischemic attack: a scientific statement for healthcare professionals from the American Heart Association/American Stroke Association Stroke Council; Council on Cardiovascular Surgery and Anesthesia; Council on Cardiovascular Radiology and Intervention; Council on Cardiovascular Nursing; and the Interdisciplinary Council on Peripheral Vascular Disease. The American Academy of Neurology affirms the value of this statement as an educational tool for neurologists. Stroke. 2009;40(6):2276-2293.

10. Johnson S, Baraboutis JG. Adverse effects associated with use of nevirapine in HIV postexposure prophylaxis for 2 health care workers. JAMA. 2000;284(21):2722-2723.

11. Rothwell PM, Warlow CP. Timing of TIAs preceding stroke: time window for prevention is very short. Neurology. 2005;64(5):817-820.

12. Bassetti C, Aldrich MS, Chervin RD, Quint D. Sleep apnea in patients with transient ischemic attack and stroke: a prospective study of 59 patients. Neurology. 1996;47(5):1167-1173.

13. Chan W, Coutts SB, Hanly P. Sleep apnea in patients with transient ischemic attack and minor stroke: opportunity for risk reduction of recurrent stroke? Stroke. 2010;41(12):2973-2975.

14. Pressman MR, Schetman WR, Figueroa WG, Van Uitert B, Caplan HJ, Peterson DD. Transient ischemic attacks and minor stroke during sleep. Relationship to obstructive sleep apnea syndrome. Stroke. 1995;26(12):2361-2365.

15. Bravata DM, Concato J, Fried T, et al. Auto-titrating continuous positive airway pressure for patients with acute transient ischemic attack: a randomized feasibility trial. Stroke. 2010;41(7):1464-1470.

16. McArdle N, Riha RL, Vennelle M, et al. Sleep-disordered breathing as a risk factor for cerebrovascular disease: a case-control study in patients with transient ischemic attacks. Stroke. 2003;34(12):2916-2921.

17. Brown DL, Bapuraj JR, Mukherji SK, et al. MRI of the pharynx in ischemic stroke patients with and without obstructive sleep apnea. Sleep Med. 2010;11(6):540-544.

18. Johnson KG, Johnson DC. Frequency of sleep apnea in stroke and TIA patients: a meta-analysis. J Clin Sleep Med. 2010;6(2):131-137.

19. Tikare SK, Chaudhary BA, Bandisode MS. Hypertension and stroke in a young man with obstructive sleep apnea syndrome. Postgrad Med. 1985;78(7):59-60, 64-66.

20. Kapen S, Park A, Goldberg J, Wynter J. The incidence and severity of OSA in ischemic cerebrovascular disease. Neurology. 1991;41(Suppl 1): 125 .

21. Spriggs DA, French JM, Murdy JM, Curless RH, Bates D, James OF Snoring increases the risk of stroke and adversely affects prognosis QJ Med. 1992;83(303):555-562.

22. Partinen M, Palomaki H. Snoring and cerebral infarction. Lancet. 1985;2(8468):1325-1326.

23. Palomaki H. Snoring and the risk of ischemic brain infarction. Stroke. 1991;22(8):1021-1025.

24. Neau JP, Meurice JC, Paquereau J, Chavagnat JJ, Ingrand P, Gil R. Habitual snoring as a risk factor for brain infarction. Acta Neurol Scand. 1995;92(1):63-68.
25. Koskenvuo M, Kaprio J, Heikkila K, Sarna S, Telakivi T, Partinen M. Snoring as a risk factor for ischaemic heart disease and stroke in men. Br Med J (Clin Res Ed). 1987;294(6572):643.

26. Hu FB, Willett WC, Manson JE, et al. Snoring and risk of cardiovascular disease in women. J Am Coll Cardiol. 2000;35(2):308-313.

27. Shahar E, Whitney CW, Redline S, et al. Sleep-disordered breathing and cardiovascular disease: cross-sectional results of the Sleep Heart Health Study. Am J Respir Crit Care Med. 2001;163(1):19-25.

28. Arzt M, Young T, Finn L, Skatrud JB, Bradley TD. Association of sleep-disordered breathing and the occurrence of stroke. Am J Respir Crit Care Med. 2005;172(11):1447-1451.

29. Redline S, Yenokyan G, Gottlieb DJ, et al. Obstructive sleep apneahypopnea and incident stroke: the sleep heart health study. Am J Respir Crit Care Med. 2010;182(2):269-277.

30. Yaggi HK, Concato J, Kernan WN, Lichtman JH, Brass LM, Mohsenin V. Obstructive sleep apnea as a risk factor for stroke and death. N Engl J Med. 2005;353(19):2034-2041.

31. Munoz R, Duran-Cantolla J, Martinez-Vila E, et al. Severe sleep apnea and risk of ischemic stroke in the elderly. Stroke. 2006;37(9): 2317-2321.

32. Valham F, Mooe T, Rabben T, Stenlund H, Wiklund U, Franklin KA. Increased risk of stroke in patients with coronary artery disease and sleep apnea: a 10-year follow-up. Circulation. 2008;118(9):955-960.

33. Kaneko Y, Hajek VE, Zivanovic V, Raboud J, Bradley TD. Relationship of sleep apnea to functional capacity and length of hospitalization following stroke. Sleep. 2003;26(3):293-297.

34. Cherkassky T, Oksenberg A, Froom P, Ring H. Sleep-related breathing disorders and rehabilitation outcome of stroke patients: a prospective study. Am J Phys Med Rehabil. 2003;82(6):452-455.

35. Rola R, Jarosz H, Wierzbicka A, et al. Sleep disordered breathing and recurrence of cerebrovascular events, case-fatality, and functional outcome in patients with ischemic stroke or transient ischemic attack. J Physiol Pharmacol. 2008;59 Suppl 6:615-621.

36. Bassetti C, Aldrich MS. Sleep apnea in acute cerebrovascular diseases: final report on 128 patients. Sleep. 1999;22(2):217-223.

37. Good DC, Henkle JQ, Gelber D, Welsh J, Verhulst S. Sleepdisordered breathing and poor functional outcome after stroke. Stroke. 1996;27(2):252-259.

38. Parra O, Sanchez-Armengol A, Bonnin M, et al. Early treatment of obstructive apnoea and stroke outcome: a randomised controlled trial. Eur Respir J. 2011;37(5):1128-1136.

39. Turkington PM, Bamford J, Wanklyn P, Elliott MW. Effect of upper airway obstruction on blood pressure variability after stroke. Clin Sci (Lond). 2004;107(1):75-79.

40. Yan-fang S, Yu-ping W. Sleep-disordered breathing: impact on functional outcome of ischemic stroke patients. Sleep Med. 2009;10(7):717-719.

41. Sahlin C, Sandberg O, Gustafson Y, et al. Obstructive sleep apnea is a risk factor for death in patients with stroke: a 10-year follow-up. Arch Intern Med. 2008;168(3):297-301.

42. Martinez-Garcia MA, Soler-Cataluna JJ, Ejarque-Martinez L, et al. Continuous positive airway pressure treatment reduces mortality in patients with ischemic stroke and obstructive sleep apnea: a 5-year follow-up study. Am J Respir Crit Care Med. 2009;180(1):36-41.

43. Martinez-Garcia MA, Campos-Rodriguez F, Soler-Cataluna JJ, CatalanSerra P, Roman-Sanchez P, Montserrat JM. Increased incidence of non-fatal cardiovascular events in stroke patients with sleep apnoea. Effect of CPAP treatment. Eur Respir J. 2011. [Epub ahead of print].

44. Hsu CY, Vennelle M, Li HY, Engleman HM, Dennis MS, Douglas NJ. Sleep-disordered breathing after stroke: a randomised controlled trial of continuous positive airway pressure. J Neurol Neurosurg Psychiatry. 2006;77(10):1143-1149.

45. Ryan CM, Bayley M, Green R, Murray BJ, Bradley TD. Influence of continuous positive airway pressure on outcomes of rehabilitation in stroke patients with obstructive sleep apnea. Stroke. 2011;42(4):1062-1067.

46. Palombini L, Guilleminault C. Stroke and treatment with nasal CPAP. Eur J Neurol. 2006;13(2):198-200. 
47. Broadley SA, Jorgensen L, Cheek A, et al. Early investigation and treatment of obstructive sleep apnoea after acute stroke. J Clin Neurosci. 2007;14(4):328-333.

48. Scala R, Turkington PM, Wanklyn P, Bamford J, Elliott MW. Acceptance, effectiveness and safety of continuous positive airway pressure in acute stroke: a pilot study. Respir Med. 2009;103(1):59-66.

49. Bassetti CL, Milanova M, Gugger M. Sleep-disordered breathing and acute ischemic stroke: diagnosis, risk factors, treatment, evolution, and long-term clinical outcome. Stroke. 2006;37(4):967-972.

50. Hui DS, Choy DK, Li TS, et al. Determinants of continuous positive airway pressure compliance in a group of Chinese patients with obstructive sleep apnea. Chest. 2001;120(1):170-176.

51. Disler P, Hansford A, Skelton J, et al. Diagnosis and treatment of obstructive sleep apnea in a stroke rehabilitation unit: a feasibility study. Am J Phys Med Rehabil. 2002;81(8):622-625.

52. Sandberg O, Franklin KA, Bucht G, Eriksson S, Gustafson Y. Nasal continuous positive airway pressure in stroke patients with sleep apnoea: a randomized treatment study. Eur Respir J. 2001;18(4):630-634.

53. Wessendorf TE, Wang YM, Thilmann AF, Sorgenfrei U, Konietzko N, Teschler H. Treatment of obstructive sleep apnoea with nasal continuous positive airway pressure in stroke. Eur Respir J. 2001;18(4): 623-629.

54. Bravata DM, Concato J, Fried T, et al. Continuous positive airway pressure: evaluation of a novel therapy for patients with acute ischemic stroke. Sleep. 2011;34(9):1271-1277.

55. Tsivgoulis G, Zhang Y, Alexandrov AW, et al. Safety and tolerability of early noninvasive ventilatory correction using bilevel positive airway pressure in acute ischemic stroke. Stroke. 2011;42(4):1030-1034.

56. Haba-Rubio J, Andries D, Rey V, Michel P, Tafti M, Heinzer R. Effect of transnasal insufflation on sleep disordered breathing in acute stroke: a preliminary study. Sleep Breath. 2011. [Epub ahead of print.]

57. Hornyak M, Cejnar M, Elam M, Matousek M, Wallin BG. Sympathetic muscle nerve activity during sleep in man. Brain. 1991;114(Pt 3): 1281-1295.

58. Mancia G. Autonomic modulation of the cardiovascular system during sleep. N Engl J Med. 1993;328(5):347-349.

59. Shepard JW Jr. Gas exchange and hemodynamics during sleep. Med Clin North Am. 1985;69(6):1243-1264.

60. Somers VK, Dyken ME, Mark AL, Abboud FM. Sympathetic-nerve activity during sleep in normal subjects. $N$ Engl $J$ Med. 1993;328(5): 303-307.

61. Orem J, Osorio I, Brooks E, Dick T. Activity of respiratory neurons during NREM sleep. J Neurophysiol. 1985;54(5):1144-1156.

62. Phillipson EA. Control of breathing during sleep. Am Rev Respir Dis. 1978;118(5):909-939.

63. Snyder F, Hobson JA, Morrison DF, Goldfrank F. Changes In respiration, heart rate, and systolic blood pressure in human sleep. $J$ Appl Physiol. 1964;19:417-422.

64. Marler JR, Price TR, Clark GL, et al. Morning increase in onset of ischemic stroke. Stroke. 1989;20(4):473-476.

65. Turin TC, Kita Y, Rumana N, et al. Morning surge in circadian periodicity of ischaemic stroke is independent of conventional risk factor status: findings from the Takashima Stroke Registry 1990-2003. Eur J Neurol. 2009;16(7):843-851.

66. Mohsenin V, Valor R. Sleep apnea in patients with hemispheric stroke. Arch Phys Med Rehabil. 1995;76(1):71-76.

67. Martinez Garcia MA, Galiano Blancart R, Cabero Salt L, Soler Cataluna JJ, Escamilla T, Roman Sanchez P. Prevalence of sleep-disordered breathing in patients with acute ischemic stroke: influence of onset time of stroke. Arch Bronconeumol. 2004;40(5):196-202.

68. Iranzo A, Santamaria J, Berenguer J, Sanchez M, Chamorro A. Prevalence and clinical importance of sleep apnea in the first night after cerebral infarction. Neurology. 2002;58(6):911-916.

69. Serizawa T, Vogel WM, Apstein CS, Grossman W. Comparison of acute alterations in left ventricular relaxation and diastolic chamber stiffness induced by hypoxia and ischemia. Role of myocardial oxygen supply-demand imbalance. J Clin Invest. 1981;68(1):91-102.
70. Leung RS, Bradley TD. Sleep apnea and cardiovascular disease. Am J Respir Crit Care Med. 2001;164(12):2147-2165.

71. Nakao K, Ohgushi M, Yoshimura M, et al. Hyperventilation as a specific test for diagnosis of coronary artery spasm. Am J Cardiol. 1997;80(5):545-549.

72. Beardslee MA, Lerner DL, Tadros PN, et al. Dephosphorylation and intracellular redistribution of ventricular connexin43 during electrical uncoupling induced by ischemia. Circ Res. 2000;87(8):656-662.

73. Wu J, McHowat J, Saffitz JE, Yamada KA, Corr PB. Inhibition of gap junctional conductance by long-chain acylcarnitines and their preferential accumulation in junctional sarcolemma during hypoxia. Circ Res. 1993;72(4):879-889.

74. Naughton M, Benard D, Tam A, Rutherford R, Bradley TD. Role of hyperventilation in the pathogenesis of central sleep apneas in patients with congestive heart failure. Am Rev Respir Dis. 1993;148(2):330-338.

75. Xie A, Wong B, Phillipson EA, Slutsky AS, Bradley TD. Interaction of hyperventilation and arousal in the pathogenesis of idiopathic central sleep apnea. Am J Respir Crit Care Med. 1994;150(2):489-495.

76. Horner RL, Rivera MP, Kozar LF, Phillipson EA. The ventilatory response to arousal from sleep is not fully explained by differences in CO(2) levels between sleep and wakefulness. J Physiol. 2001;534(Pt 3): 881-890.

77. O’Donnell CP, Ayuse T, King ED, Schwartz AR, Smith PL, Robotham JL. Airway obstruction during sleep increases blood pressure without arousal. J Appl Physiol. 1996;80(3):773-781.

78. Trinder J, Merson R, Rosenberg JI, Fitzgerald F, Kleiman J, Douglas Bradley T. Pathophysiological interactions of ventilation, arousals, and blood pressure oscillations during cheyne-stokes respiration in patients with heart failure. Am J Respir Crit Care Med. 2000;162(3 Pt 1): 808-813.

79. Horner RL, Brooks D, Kozar LF, Tse S, Phillipson EA. Immediate effects of arousal from sleep on cardiac autonomic outflow in the absence of breathing in dogs. J Appl Physiol. 1995;79(1):151-162.

80. Suzuki M, Ogawa H, Okabe S, et al. Digital recording and analysis of esophageal pressure for patients with obstructive sleep apnea-hypopnea syndrome. Sleep Breath. 2005;9(2):64-72.

81. Virolainen J, Ventila M, Turto H, Kupari M. Influence of negative intrathoracic pressure on right atrial and systemic venous dynamics. Eur Heart J. 1995;16(9):1293-1299.

82. Balfors EM, Franklin KA. Impairment of cerebral perfusion during obstructive sleep apneas. Am J Respir Crit Care Med. 1994;150(6 Pt 1): 1587-1591.

83. Nasr N, Traon AP, Czosnyka M, Tiberge M, Schmidt E, Larrue V. Cerebral autoregulation in patients with obstructive sleep apnea syndrome during wakefulness. Eur J Neurol. 2009;16(3):386-391.

84. Hayakawa T, Terashima M, Kayukawa Y, Ohta T, Okada T. Changes in cerebral oxygenation and hemodynamics during obstructive sleep apneas. Chest. 1996;109(4):916-921.

85. Somers VK, Dyken ME, Clary MP, Abboud FM. Sympathetic neural mechanisms in obstructive sleep apnea. J Clin Invest. 1995;96(4):1897-1904.

86. Patel MB, Stewart JM, Loud AV, et al. Altered function and structure of the heart in dogs with chronic elevation in plasma norepinephrine. Circulation. 1991;84(5):2091-2100.

87. Schlaich MP, Kaye DM, Lambert E, Sommerville M, Socratous F, Esler MD. Relation between cardiac sympathetic activity and hypertensive left ventricular hypertrophy. Circulation. 2003;108(5):560-565.

88. Kamba M, Suto Y, Ohta Y, Inoue Y, Matsuda E. Cerebral metabolism in sleep apnea. Evaluation by magnetic resonance spectroscopy. Am J Respir Crit Care Med. 1997;156(1):296-298.

89. Sander D, Winbeck K, Klingelhofer J, Etgen T, Conrad B. Prognostic relevance of pathological sympathetic activation after acute thromboembolic stroke. Neurology. 2001;57(5):833-838.

90. De Caterina R, Libby P, Peng HB, et al. Nitric oxide decreases cytokineinduced endothelial activation. Nitric oxide selectively reduces endothelial expression of adhesion molecules and proinflammatory cytokines. J Clin Invest. 1995;96(1):60-68. 
91. Dworakowski R, Alom-Ruiz SP, Shah AM. NADPH oxidase-derived reactive oxygen species in the regulation of endothelial phenotype. Pharmacol Rep. 2008;60(1):21-28.

92. Barnes PJ, Karin M. Nuclear factor-kappaB: a pivotal transcription factor in chronic inflammatory diseases. NEngl J Med. 1997;336(15): 1066-1071.

93. Ross R. Atherosclerosis is an inflammatory disease. Am Heart J. 1999;138(5 Pt 2):S419-S420.

94. Ip MS, Tse HF, Lam B, Tsang KW, Lam WK. Endothelial function in obstructive sleep apnea and response to treatment. Am J Respir Crit Care Med. 2004;169(3):348-353.

95. Lavie L, Lavie P. Molecular mechanisms of cardiovascular disease in OSAHS: the oxidative stress link. Eur Respir J. 2009;33(6): 1467-1484.

96. Juranek I, Bezek S. Controversy of free radical hypothesis: reactive oxygen species - cause or consequence of tissue injury? Gen Physiol Biophys. 2005;24(3):263-278.

97. Ryan S, Taylor CT, McNicholas WT. Selective activation of inflammatory pathways by intermittent hypoxia in obstructive sleep apnea syndrome. Circulation. 2005;112(17):2660-2667.

98. Garvey JF, Taylor CT, McNicholas WT. Cardiovascular disease in obstructive sleep apnoea syndrome: the role of intermittent hypoxia and inflammation. Eur Respir J. 2009;33(5):1195-1205.

99. Dyugovskaya L, Lavie P, Lavie L. Increased adhesion molecules expression and production of reactive oxygen species in leukocytes of sleep apnea patients. Am J Respir Crit Care Med. 2002;165(7): 934-939.

100. Ohga E, Nagase T, Tomita T, et al. Increased levels of circulating ICAM-1, VCAM-1, and L-selectin in obstructive sleep apnea syndrome. J Appl Physiol. 1999;87(1):10-14.

101. Steiropoulos P, Kotsianidis I, Nena E, et al. Long-term effect of continuous positive airway pressure therapy on inflammation markers of patients with obstructive sleep apnea syndrome. Sleep. 2009;32(4):537-543.

102. Tazaki T, Minoguchi K, Yokoe T, et al. Increased levels and activity of matrix metalloproteinase-9 in obstructive sleep apnea syndrome. Am J Respir Crit Care Med. 2004;170(12):1354-1359.

103. Mun-Bryce S, Rosenberg GA. Matrix metalloproteinases in cerebrovascular disease. J Cereb Blood Flow Metab. 1998;18(11): 1163-1172.

104. Beal MF. Aging, energy, and oxidative stress in neurodegenerative diseases. Ann Neurol. 1995;38(3):357-366.

105. Butterfield D, Castegna A, Pocernich C, Drake J, Scapagnini G, Calabrese V. Nutritional approaches to combat oxidative stress in Alzheimer's disease. J Nutr Biochem. 2002;13(8):444.

106. Wang Y, Zhang SX, Gozal D. Reactive oxygen species and the brain in sleep apnea. Respir Physiol Neurobiol. 2010;174(3):307-316.

107. Medeiros CA, de Bruin VM, Andrade GM, Coutinho WM, de CastroSilva C, de Bruin PF. Obstructive sleep apnea and biomarkers of inflammation in ischemic stroke. Acta Neurol Scand. 2011. [Epub ahead of print].

108. Dyugovskaya L, Polyakov A, Lavie P, Lavie L. Delayed neutrophil apoptosis in patients with sleep apnea. Am J Respir Crit Care Med. 2008;177(5):544-554.

109. Dyugovskaya L, Lavie P, Hirsh M, Lavie L. Activated CD8+ T-lymphocytes in obstructive sleep apnoea. Eur Respir J. 2005;25(5): $820-828$.

110. Dyugovskaya L, Lavie P, Lavie L. Phenotypic and functional characterization of blood gammadelta T cells in sleep apnea. Am J Respir Crit Care Med. 2003;168(2):242-249.

111. Dyugovskaya L, Lavie P, Lavie L. Lymphocyte activation as a possible measure of atherosclerotic risk in patients with sleep apnea. Ann NY Acad Sci. 2005;1051:340-350.

112. Nishioka T, Suzuki M, Onishi K, et al. Eplerenone attenuates myocardial fibrosis in the angiotensin II-induced hypertensive mouse: involvement of tenascin-C induced by aldosterone-mediated inflammation. J Cardiovasc Pharmacol. 2007;49(5):261-268.
113. Stas S, Whaley-Connell A, Habibi J, et al. Mineralocorticoid receptor blockade attenuates chronic overexpression of the reninangiotensin-aldosterone system stimulation of reduced nicotinamide adenine dinucleotide phosphate oxidase and cardiac remodeling. Endocrinology. 2007;148(8):3773-3780.

114. Moller DS, Lind P, Strunge B, Pedersen EB. Abnormal vasoactive hormones and 24-hour blood pressure in obstructive sleep apnea. Am J Hypertens. 2003;16(4):274-280.

115. Touyz RM. Oxidative stress and vascular damage in hypertension. Curr Hypertens Rep. 2000;2(1):98-105.

116. Takahashi S, Nakamura Y, Nishijima T, Sakurai S, Inoue H. Essential roles of angiotensin II in vascular endothelial growth factor expression in sleep apnea syndrome. Respir Med. 2005;99(9):1125-1131.

117. Takahashi H, Yoshika M, Komiyama Y, Nishimura M. The central mechanism underlying hypertension: a review of the roles of sodium ions, epithelial sodium channels, the renin-angiotensin-aldosterone system, oxidative stress and endogenous digitalis in the brain. Hypertens Res. 2011;34(11):1147-1160.

118. Drager LF, Polotsky VY, Lorenzi-Filho G. Obstructive sleep apnea: an emerging risk factor for atherosclerosis. Chest. 2011;140(2): 534-542.

119. Montagnani M, Golovchenko I, Kim I, et al. Inhibition of phosphatidylinositol 3-kinase enhances mitogenic actions of insulin in endothelial cells. J Biol Chem. 2002;277(3):1794-1799.

120. Sowers JR. Hypertension, angiotensin II, and oxidative stress. N Engl J Med. 2002;346(25):1999-2001.

121. Polak JF, Pencina MJ, O’Leary DH, D’Agostino RB. Common carotid artery intima-media thickness progression as a predictor of stroke in multi-ethnic study of atherosclerosis. Stroke. 2011;42(11): 3017-3021.

122. Bots ML, Hoes AW, Koudstaal PJ, Hofman A, Grobbee DE. Common carotid intima-media thickness and risk of stroke and myocardial infarction: the Rotterdam Study. Circulation. 1997;96(5):1432-1437.

123. O’Leary DH, Polak JF, Kronmal RA, Manolio TA, Burke GL, Wolfson SK Jr. Carotid-artery intima and media thickness as a risk factor for myocardial infarction and stroke in older adults. Cardiovascular Health Study Collaborative Research Group. N Engl J Med. 1999;340(1):14-22.

124. Chambless LE, Folsom AR, Clegg LX, et al. Carotid wall thickness is predictive of incident clinical stroke: the Atherosclerosis Risk in Communities (ARIC) study. Am J Epidemiol. 2000;151(5):478-487.

125. Drager LF, Bortolotto LA, Lorenzi MC, Figueiredo AC, Krieger EM, Lorenzi-Filho G. Early signs of atherosclerosis in obstructive sleep apnea. Am J Respir Crit Care Med. 2005;172(5):613-618.

126. Drager LF, Bortolotto LA, Maki-Nunes C, et al. The incremental role of obstructive sleep apnoea on markers of atherosclerosis in patients with metabolic syndrome. Atherosclerosis. 2010;208(2):490-495.

127. Drager LF, Bortolotto LA, Krieger EM, Lorenzi-Filho G. Additive effects of obstructive sleep apnea and hypertension on early markers of carotid atherosclerosis. Hypertension. 2009;53(1):64-69.

128. Nachtmann A, Stang A, Wang YM, Wondzinski E, Thilmann AF. Association of obstructive sleep apnea and stenotic artery disease in ischemic stroke patients. Atherosclerosis. 2003;169(2): 301-307.

129. Dziewas R, Ritter M, Usta N, et al. Atherosclerosis and obstructive sleep apnea in patients with ischemic stroke. Cerebrovasc Dis. 2007;24(1):122-126.

130. Gorelick PB. New horizons for stroke prevention: PROGRESS and HOPE. Lancet Neurol. 2002;1(3):149-156.

131. Lammie GA. Hypertensive cerebral small vessel disease and stroke. Brain Pathol. 2002;12(3):358-370.

132. Schwartz GL, Bailey KR, Mosley T, et al. Association of ambulatory blood pressure with ischemic brain injury. Hypertension. 2007;49(6): 1228-1234.

133. Dolan E, Stanton A, Thijs L, et al. Superiority of ambulatory over clinic blood pressure measurement in predicting mortality: the Dublin outcome study. Hypertension. 2005;46(1):156-161. 
134. Law MR, Morris JK, Wald NJ. Use of blood pressure lowering drugs in the prevention of cardiovascular disease: meta-analysis of 147 randomised trials in the context of expectations from prospective epidemiological studies. BMJ. 2009;338:b1665.

135. Cooper VL, Pearson SB, Bowker CM, Elliott MW, Hainsworth R. Interaction of chemoreceptor and baroreceptor reflexes by hypoxia and hypercapnia - a mechanism for promoting hypertension in obstructive sleep apnoea. $J$ Physiol. 2005;568(Pt 2):677-687.

136. Allahdadi KJ, Walker BR, Kanagy NL. Augmented endothelin vasoconstriction in intermittent hypoxia-induced hypertension. Hypertension. 2005;45(4):705-709.

137. Young T, Peppard P, Palta M, et al. Population-based study of sleepdisordered breathing as a risk factor for hypertension. Arch Intern Med. 1997;157(15):1746-1752.

138. Alajmi M, Mulgrew AT, Fox J, et al. Impact of continuous positive airway pressure therapy on blood pressure in patients with obstructive sleep apnea hypopnea: a meta-analysis of randomized controlled trials. Lung. 2007;185(2):67-72.

139. Bazzano LA, Khan Z, Reynolds K, He J. Effect of nocturnal nasal continuous positive airway pressure on blood pressure in obstructive sleep apnea. Hypertension. 2007;50(2):417-423.

140. Haentjens P, Van Meerhaeghe A, Moscariello A, et al. The impact of continuous positive airway pressure on blood pressure in patients with obstructive sleep apnea syndrome: evidence from a metaanalysis of placebo-controlled randomized trials. Arch Intern Med. 2007;167(8):757-764.

141. Nieto FJ, Young TB, Lind BK, et al. Association of sleep-disordered breathing, sleep apnea, and hypertension in a large communitybased study. Sleep Heart Health Study. JAMA. 2000;283(14): 1829-1836.

142. Peppard PE, Young T, Palta M, Skatrud J. Prospective study of the association between sleep-disordered breathing and hypertension. N Engl J Med. 2000;342(19):1378-1384.

143. O'Connor GT, Caffo B, Newman AB, et al. Prospective study of sleepdisordered breathing and hypertension: the Sleep Heart Health Study. Am J Respir Crit Care Med. 2009;179(12):1159-1164.

144. Logan AG, Perlikowski SM, Mente A, et al. High prevalence of unrecognized sleep apnoea in drug-resistant hypertension. $J$ Hypertens. 2001;19(12):2271-2277.

145. Grote L, Hedner J, Peter JH. Sleep-related breathing disorder is an independent risk factor for uncontrolled hypertension. J Hypertens. 2000;18(6):679-685

146. Lip GY, Zarifis J, Farooqi IS, Page A, Sagar G, Beevers DG. Ambulatory blood pressure monitoring in acute stroke. The West Birmingham Stroke Project. Stroke. 1997;28(1):31-35.

147. Morfis L, Schwartz RS, Poulos R, Howes LG. Blood pressure changes in acute cerebral infarction and hemorrhage. Stroke. 1997;28(7): 1401-1405.

148. Bhalla A, Wolfe CD, Rudd AG. The effect of $24 \mathrm{~h}$ blood pressure levels on early neurological recovery after stroke. J Intern Med. 2001;250(2):121-130.

149. Castillo J, Leira R, Garcia MM, Serena J, Blanco M, Davalos A. Blood pressure decrease during the acute phase of ischemic stroke is associated with brain injury and poor stroke outcome. Stroke. 2004;35(2):520-526.

150. Selic C, Siccoli MM, Hermann DM, Bassetti CL. Blood pressure evolution after acute ischemic stroke in patients with and without sleep apnea. Stroke. 2005;36(12):2614-2618.

151. Johansson L, Jansson JH, Boman K, Nilsson TK, Stegmayr B, Hallmans G. Tissue plasminogen activator, plasminogen activator inhibitor-1, and tissue plasminogen activator/plasminogen activator inhibitor-1 complex as risk factors for the development of a first stroke. Stroke. 2000;31(1):26-32.

152. Wiklund PG, Nilsson L, Ardnor SN, et al. Plasminogen activator inhibitor-1 $4 \mathrm{G} / 5 \mathrm{G}$ polymorphism and risk of stroke: replicated findings in two nested case-control studies based on independent cohorts. Stroke. 2005;36(8):1661-1665.
153. Guardiola JJ, Matheson PJ, Clavijo LC, Wilson MA, Fletcher EC. Hypercoagulability in patients with obstructive sleep apnea. Sleep Med. 2001;2(6):517-523.

154. Nobili L, Schiavi G, Bozano E, De Carli F, Ferrillo F, Nobili F. Morning increase of whole blood viscosity in obstructive sleep apnea syndrome. Clin Hemorheol Microcirc. 2000;22(1):21-27.

155. von Kanel R, Le DT, Nelesen RA, Mills PJ, Ancoli-Israel S, Dimsdale JE. The hypercoagulable state in sleep apnea is related to comorbid hypertension. J Hypertens. 2001;19(8):1445-1451.

156. Hui DS, Ko FW, Fok JP, et al. The effects of nasal continuous positive airway pressure on platelet activation in obstructive sleep apnea syndrome. Chest. 2004;125(5):1768-1775.

157. Reinhart WH, Oswald J, Walter R, Kuhn M. Blood viscosity and platelet function in patients with obstructive sleep apnea syndrome treated with nasal continuous positive airway pressure. Clin Hemorheol Microcirc. 2002;27(3-4):201-207.

158. Brown NJ, Agirbasli MA, Williams GH, Litchfield WR, Vaughan DE. Effect of activation and inhibition of the renin-angiotensin system on plasma PAI-1. Hypertension. 1998;32(6):965-971.

159. Eisensehr I, Ehrenberg BL, Noachtar S, et al. Platelet activation, epinephrine, and blood pressure in obstructive sleep apnea syndrome. Neurology. 1998;51(1):188-195.

160. Rangemark C, Hedner JA, Carlson JT, Gleerup G, Winther K. Platelet function and fibrinolytic activity in hypertensive and normotensive sleep apnea patients. Sleep. 1995;18(3):188-194.

161. Sanner BM, Konermann M, Tepel M, Groetz J, Mummenhoff C, Zidek W. Platelet function in patients with obstructive sleep apnoea syndrome. Eur Respir J. 2000;16(4):648-652.

162. Wessendorf TE, Thilmann AF, Wang YM, Schreiber A, Konietzko N, Teschler H. Fibrinogen levels and obstructive sleep apnea in ischemic stroke. Am J Respir Crit Care Med. 2000;162(6):2039-2042.

163. Guilleminault C, Connolly SJ, Winkle RA. Cardiac arrhythmia and conduction disturbances during sleep in 400 patients with sleep apnea syndrome. Am J Cardiol. 1983;52(5):490-494.

164. Mehra R, Benjamin EJ, Shahar E, et al. Association of nocturnal arrhythmias with sleep-disordered breathing: The Sleep Heart Health Study. Am J Respir Crit Care Med. 2006;173(8):910-916.

165. Mehra R, Stone KL, Varosy PD, et al. Nocturnal Arrhythmias across a spectrum of obstructive and central sleep-disordered breathing in older men: outcomes of sleep disorders in older men (MrOS sleep) study. Arch Intern Med. 2009;169(12):1147-1155.

166. Guilleminault C, Connolly SJ, Winkle RA. Cardiac arrhythmia and conduction disturbances during sleep in 400 patients with sleep apnea syndrome. Am J Cardiol. 1983;52(5):490-494.

167. Kanagala R, Murali NS, Friedman PA, et al. Obstructive sleep apnea and the recurrence of atrial fibrillation. Circulation. 2003;107(20): 2589-2594.

168. Olmetti F, La Rovere MT, Robbi E, Taurino AE, Fanfulla F. Nocturnal cardiac arrhythmia in patients with obstructive sleep apnea. Sleep Med. 2008;9(5):475-480.

169. Tanigawa T, Yamagishi K, Sakurai S, et al. Arterial oxygen desaturation during sleep and atrial fibrillation. Heart. 2006;92(12):1854-1855.

170. Gami AS, Hodge DO, Herges RM, et al. Obstructive sleep apnea, obesity, and the risk of incident atrial fibrillation. $\mathrm{J} \mathrm{Am} \mathrm{Coll} \mathrm{Cardiol.}$ 2007;49(5):565-571.

171. Serena J, Jimenez-Nieto M, Silva Y, Castellanos M. Patent foramen ovale in cerebral infarction. Curr Cardiol Rev. 2010;6(3):162-174.

172. Gu X, He Y, Li Z, et al. Comparison of frequencies of patent foramen ovale and thoracic aortic atherosclerosis in patients with cryptogenic ischemic stroke undergoing transesophageal echocardiography. Am J Cardiol. 2011. [Epub ahead of print].

173. Pezzini A, Del Zotto E, Magoni M, et al. Inherited thrombophilic disorders in young adults with ischemic stroke and patent foramen ovale. Stroke. 2003;34(1):28-33.

174. Lau EM, Jaijee SK, Melehan KL, et al. Prevalence of patent foramen ovale and its impact on oxygen desaturation in obstructive sleep apnea. Int J Cardiol. 2011. [Epub ahead of print]. 
175. Beelke M, Angeli S, Del Sette M, et al. Obstructive sleep apnea can be provocative for right-to-left shunting through a patent foramen ovale. Sleep. 2002;25(8):856-862.

176. Wendel-Vos GC, Schuit AJ, Feskens EJ, et al. Physical activity and stroke. A meta-analysis of observational data. Int J Epidemiol. 2004;33(4):787-798.

177. Lakka TA, Salonen JT. Moderate to high intensity conditioning leisure time physical activity and high cardiorespiratory fitness are associated with reduced plasma fibrinogen in eastern Finnish men. $J$ Clin Epidemiol. 1993;46(10):1119-1127.

178. Manson JE, Colditz GA, Stampfer MJ, et al. A prospective study of maturity-onset diabetes mellitus and risk of coronary heart disease and stroke in women. Arch Intern Med. 1991;151(6):1141-1147.

179. Chasens ER, Sereika SM, Houze MP, Strollo PJ. Subjective and objective appraisal of activity in adults with obstructive sleep apnea. J Aging Res. 2011;2011:751819.

180. Peppard PE, Young T. Exercise and sleep-disordered breathing: an association independent of body habitus. Sleep. 2004;27(3):480-484.

181. Vasquez MM, Goodwin JL, Drescher AA, Smith TW, Quan SF. Associations of dietary intake and physical activity with sleep disordered breathing in the Apnea Positive Pressure Long-Term Efficacy Study (APPLES). J Clin Sleep Med. 2008;4(5):411-418.

182. West SD, Kohler M, Nicoll DJ, Stradling JR. The effect of continuous positive airway pressure treatment on physical activity in patients with obstructive sleep apnoea: A randomised controlled trial. Sleep Med. 2009;10(9):1056-1058.

183. Redolfi S, Yumino D, Ruttanaumpawan P, et al. Relationship between overnight rostral fluid shift and Obstructive Sleep Apnea in nonobese men. Am J Respir Crit Care Med. 2009;179(3):241-246.

184. Morgan BJ, Reichmuth KJ, Peppard PE, et al. Effects of sleep disordered breathing on cerebrovascular regulation: a population-based study. Am J Respir Crit Care Med. 2010;182(11):1445-1452.

185. Zhang JH, Fung SJ, Xi M, Sampogna S, Chase MH. Recurrent apnea induces neuronal apoptosis in the guinea pig forebrain. Exp Neurol. 2009;216(2):290-294.

186. Beebe DW, Gozal D. Obstructive sleep apnea and the prefrontal cortex: towards a comprehensive model linking nocturnal upper airway obstruction to daytime cognitive and behavioral deficits. J Sleep Res. 2002;11(1):1-16.

187. Aloia MS, Arnedt JT, Davis JD, Riggs RL, Byrd D. Neuropsychological sequelae of obstructive sleep apnea-hypopnea syndrome: a critical review. J Int Neuropsychol Soc. 2004;10(5):772-785.

188. Rae C, Bartlett DJ, Yang Q, et al. Dynamic changes in brain bioenergetics during obstructive sleep apnea. J Cereb Blood Flow Metab. 2009;29(8):1421-1428.
189. Torelli F, Moscufo N, Garreffa G, et al. Cognitive profile and brain morphological changes in obstructive sleep apnea. Neuroimage. 2011;54(2):787-793.

190. Macey PM, Kumar R, Woo MA, Valladares EM, Yan-Go FL, Harper RM. Brain structural changes in obstructive sleep apnea. Sleep. 2008;31(7):967-977.

191. Morrell MJ, Jackson ML, Twigg GL, et al. Changes in brain morphology in patients with obstructive sleep apnoea. Thorax. 2010;65(10):908-914.

192. Joo EY, Tae WS, Lee MJ, et al. Reduced brain gray matter concentration in patients with obstructive sleep apnea syndrome. Sleep. 2010;33(2):235-241.

193. Canessa N, Castronovo V, Cappa SF, et al. Obstructive sleep apnea: brain structural changes and neurocognitive function before and after treatment. Am J Respir Crit Care Med. 2011;183(10):1419-1426.

194. Smith EE. Leukoaraiosis and stroke. Stroke. 2010;41(10 Suppl): S139-S143.

195. Kimberly WT, Gilson A, Rost NS, et al. Silent ischemic infarcts are associated with hemorrhage burden in cerebral amyloid angiopathy. Neurology. 2009;72(14):1230-1235.

196. Potter GM, Doubal FN, Jackson CA, et al. Counting cavitating lacunes underestimates the burden of lacunar infarction. Stroke. 2010;41(2):267-272.

197. Joo BE, Seok HY, Yu SW, et al. Prevalence of sleep-disordered breathing in acute ischemic stroke as determined using a portable sleep apnea monitoring device in Korean subjects. Sleep Breath. 2011;15(1):77-82.

198. Arzt M, Young T, Peppard PE, et al. Dissociation of obstructive sleep apnea from hypersomnolence and obesity in patients with stroke. Stroke. 2010;41(3):e129-e134.

199. Netzer NC, Stoohs RA, Netzer CM, Clark K, Strohl KP. Using the Berlin Questionnaire to identify patients at risk for the sleep apnea syndrome. Ann Intern Med. 1999;131(7):485-491.

200. Srijithesh PR, Shukla G, Srivastav A, Goyal V, Singh S, Behari M. Validity of the Berlin Questionnaire in identifying obstructive sleep apnea syndrome when administered to the informants of stroke patients. J Clin Neurosci. 2011;18(3):340-343.

201. Chen CY, Hsu CC, Pei YC, Yu CC, Chen YS, Chen CL. Nocturia is an independent predictor of severe obstructive sleep apnea in patients with ischemic stroke. J Neurol. 2011;258(2):189-194.
ChronoPhysiology and Therapy

\section{Publish your work in this journal}

ChronoPhysiology and Therapy is an international, peer-reviewed, open access journal focusing on research into the cyclic variations and rhythmicity in physiological processes in the body and the research and development and optimal timing of administration of therapeutic targets to achieve improved outcomes and quality of life for the patient. The

\section{Dovepress}

manuscript management system is completely online and includes a very quick and fair peer-review system. Visit http://www.dovepress.com/ testimonials.php to read real quotes from published authors. 